\title{
Development of the Teaching Tool to Learn the Mechanism of Wind Power Generation*
}

\author{
Toshikazu YAMAMOTO**. Koji OGIKUBO** and Takuma Nishimura*** \\ * Faculty of Education, Saitama University \\ 255 Simo-ookubo, Sakura-ku, Saitama-shi, Saitama 338-8570, Japan \\ E-mail.ogikubo@mail saitama-u.ac.jp \\ *** Cooperative Association PROD
}

21-13-3 Shimo-ejiricho, Fukui-shi, Fukui 918-8173, Japan

\begin{abstract}
The teaching tool to learn the mechanism of wind power generation in the technology education course in junior high school was developed. Developed teaching tool is a Savonius-type windmill. The magnetic levitation bcaring has been installed so that blades can lightly rotate. The rotation of the blades is accelerated by the gear, and it rotates magnets. Transformer coils has been installed under the magnets, so that the electricity is generated by the change of the magnetic field. The main body is made of transparent acrylic pipes, as the transmission of the power can be visually observed. The experimental class was performed using this teaching tool for junior high school students. As the result, it was effective for them to learn the mechanism of the wind power generation experimentally.
\end{abstract}

Key words: Wind Power Gencration, Savonius-type windmill, Teaching Tool, Technology Education, Energy Education

\section{Introduction}

In recent ycars, the interest for environmental problems and energy problems rose inside and outside Japan. The word called "new energy" is used in the course of study (governmental curriculum guidelines) ${ }^{(1)}$ and the textbook ${ }^{(2)}$ of the technology education course in junior high school, and the matters concerning it came to be learned. New energy indicates the newly developed energy which is expected to introduce in the future, compared with the conventional energy such as petroleum, coal and so on. New energy. which is a peculiar classification of energy in Japan, is prescribed as "New energy use" in "Special measures law concerning the promotion of a new encrgy usc" enforced in 1997. and defined as "the energy that is reaching the practical use stage technically. but it is not cnough spread due to an economical restriction and particularly necessary to introduce as petroleum alternative energy". Therefore, hydraulic power generation in a commercial scale in the practical use stage and wave power generation and ocean thermal energy conversion in the research and development stage are not included in new energy even if they are natural energy. Then, the definition of new energy is as follows: wind power generation, photovoltaic generation, solar heat utilization, water heat utilization. frozen snow heat utilization. biomass fuel production, biomass heat utilization, biomass power generation. geothermal power generation in binary cycle and hydraulic power generation in a small scalc. The meaning of new energy is equal to so-called "renewable cnergy".

Although the dependency on petroleum decreased by the introduction of natural gas and nuclear power, the use ratio of petroleum is still high in the world. Then, the introduction and practical use of new energy are required. Recently, wind power generation expands 
rapidly in Japan. The number of the wind power generator of the output $10 \mathrm{~kW}$ or more is 1050 , and the total capacity is about 1.08 million $\mathrm{kW}$ in March. 2006

In "New energy department report" issued in July, 2001 by the Advisory Committee for Natural Resources and Energy in the Ministry of Economy, Trade and Industry in Japan, the governmental target for the introduction of wind power generation by fiscal year 2010 is set as about 3 million $\mathrm{kW}$. Then, the construction of the wind power plant is progressed in many places in Japan. Moreover, receiving such a situation, Geographical Survey Institute in Japan began to describe the wind power plant by the figure sign, which was designed by a junior high school student, in 1/25,000 topographical map in June, 2006. As for the present state of wind power generation in the world, a commercial generation of the considerable capacity is performed in Europe and America. The total capacity of wind power generation in the world reached about 47.57 million $\mathrm{kW}$ at the end of 2004 . The introduction is advanced in (jermany ( 16.63 million $\mathrm{kW}$ ), Spain ( 8.26 million $\mathrm{kW}$ ), USA (6.75 million $\mathrm{kW}$ ), Denmark (3.12 million $\mathrm{kW}$ ) and India (2.98 million $\mathrm{kW}$ ). From these data, the ratio of the wind power generation in Japan is only $2 \%$ of the world. Then, appropriate spread activitics are required.

Therefore, in this study, we developed the teaching tool of wind power generation to apply to the primary and secondary education. The purpose of this study is to consider the content of teaching to learn the mechanism, the present state and the problems of wind power generation using the teaching tool.

\section{Developed teaching tool in this study}

\subsection{Intentions of the developed teaching tool}

In wind power generation, wind force turns the blades, and the rotary motion is conveyed to a dynamo to generate electricity. This is a relatively high efficient power generation system that can convert about $35 \%$ of the wind energy into the electric energy. By learning these facts appropriately, it is considered that the promotion of students who positively participate in the energy and environment problems becomes possible.

In the precedent studies concerning wind power generation, the observation of a small wind power generation system and the production of a simple wind power generation device were performed to raise the interest for energy and environment in the integrated learning course and the science education course in primary school ${ }^{(4)}$. In the science education course in junior high school, the production of a simple wind power generation device was performed to understand the conversion mechanism of wind energy into electric energy through the confirmation of the electromagnetic induction and the electricity generation ${ }^{(5)}$. In the technology education course in junior high school, the acquisition of the useful knowledge to help real life such as the energy conversion technology and the energy saving technology was performed through the production of a simple wind power generation device ${ }^{(6)}$.

In these studies, the mechanism of power generation by the rotation of a dynamo by the wind force was learned using a simple wind power generation device. However, though various ideas of the mechanical engineering and the electrical engineering are included in an actual wind power generation device, there is no precedent study including such ideas in the content of learning. For example, the ideas about bearing to reduce the friction of the rotation shaft. the gears to accelerate the rotation speed. the shape of blades suitable for the wind flow and so on. Moreover. it is considered that the no use of a commercially available dynamo and the direct observation of the relation between magnets and coils is very effective to understand the mechanism of power generation.

Thereforc. we tricd to develop the teaching tool of wind power generation to learn the fundamentals of the mechanical engineering and the electrical engineering as well as the mechanism of wind power generation. We selected the Savonius-type windmill as the 
developed teaching tool. In the case of a vertical axis type windmill such as the Savonius-type, the direct observation of the mechanism of power generation with magnets and coils is easier and the design of the windmill can be free, while in the case of a horizontal axis type windmill such as a propeller type, the nacelle, which is a main body of the windmill behind the propeller, should be rotated according to the direction of the wind.

The main intentions for the teaching tool development are as follows.

1. The mechanism of wind power generation and the power transmission can be learned visually.

2. The generated electricity can be learned experimentally through the measurement.

3. The idea to rotate the blades lightly can be learned.

4. The mechanism of the rotation speed acceleration to raise the power generation efficiency can be learned.

5. The relation between magnets and coils can be learned in detail.

6. The shape of blade that catches wind force efficiently can be learned.

7. It can be easy to introduce at a low price to schools.

\subsection{Features of the developed teaching tool}

Figure 1 show's the aspect of the developed teaching tool. The teaching tool is the Savonius-type vertical axis windmill. It is $400 \mathrm{~mm}$ in width, $400 \mathrm{~mm}$ in depth and $750 \mathrm{~mm}$ in height. Blades are installed at the upside of the teaching tool. Rotary motion of the blades is conveyed to the main shaft. In comparison of the Savonius-type windmill with a horizontal axis type windmill such as a propeller type. the cut-in wind velocity. which is the wind velocity when the windmill begins to generate electricity, is smaller and the structure can be more simple. Moreover, transparent acrylic pipes are used for the main body, so that the internal structure and the transmission of the power can be visually observed. The number of blades is three. Considering the efficiency, the upper part of the blade is narrow.

Figure 2 shows the aspect of the magnetic levitating bearing. To reduce the friction of the rotary shaft, the magnetic levitating type bearing is installed. Two magnets are installed to repulse cach other, so that the part of blades is levitating.

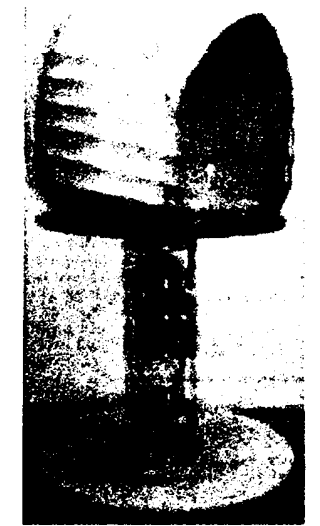

Fig. I Aspect of developed teaching tool

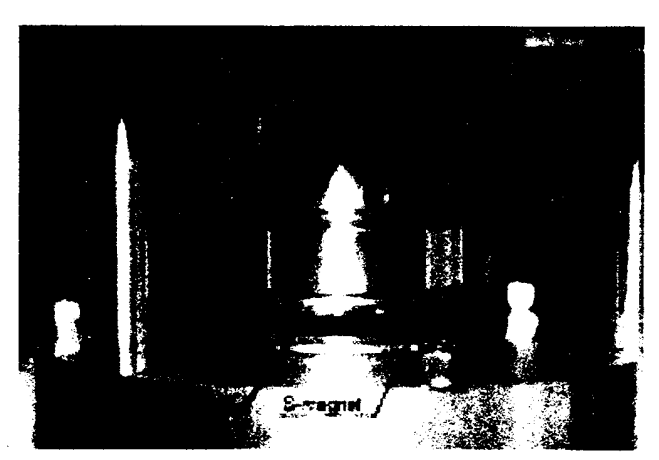

Fig. 2 Magnetic levitation bearing

Figure 3 shows the aspect of the speed acceleration gears. The rotation speed of the blades is accelerated four times in maximum by the gears, because the faster rotation of the gears can achieve the higher power generation efficiency. In this teaching tool, the rotation speed is changed two to four times by shifting the gears, and the quantity of generated electricity at the same wind velocity can be compared.

Figure 4 shows the aspect of the magnets and the transformer coils installed as the power generator. No commercially available dynamo is used as the power generator to learn the mechanism of power gencration theoretically. The magnets are fixed to the main shaft 
and the coils are installed under the magnets, so that the power generation by the electromagnetic induction can be visually learned. The neodymium magnets of $\mathrm{S}$ pole side and $\mathrm{N}$ pole side are alternately fixed on the disk, which attached to the main shaft. On a disk with the same diameter installed under the magnets, three coils are arranged at the same interval. The distance between the magnets and the coils is adjustable to change the quantity of generated electricity. By adjusting the rotation speed by the gears and the distance between magnets and the coils according to wind velocity, more efficient wind power generation can be achieved.

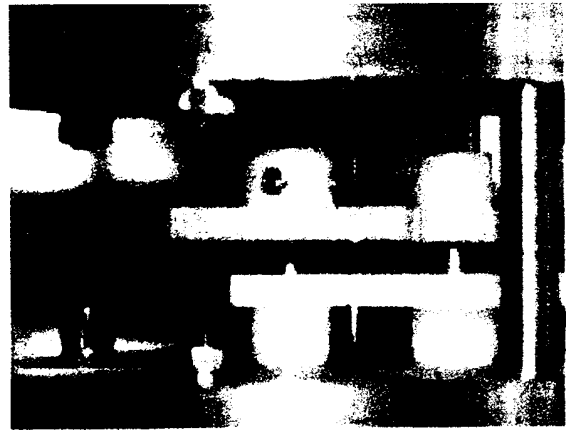

Fig. 3 Gears for rotation speed acceleration

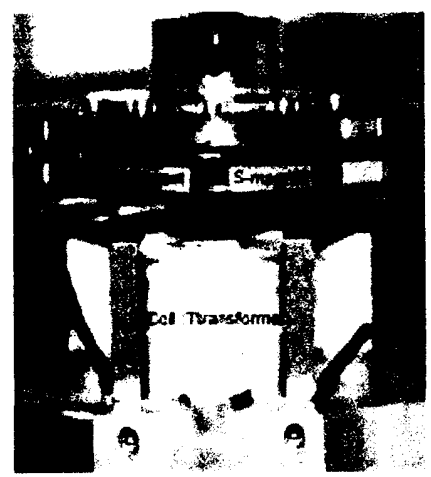

Fig. 4 Aspect of power generator

The generated electricity can be obtained at the output terminals as both the alternating current and the direct current. At the direct current output terminals, the commutation circuit is built in, and moreover, five LED light gradually according to the commutated direct current voltage. The teaching tool is wholly waterproofed to be available also outdoors. It is also possible to measure power generation during a day by connecting the output terminals to the personal computer.

\section{Practice of experimental class}

\subsection{Procedure of the experimental class}

The experimental class using the teaching tool has been performed every year from 2005. In this study, we reported about the class performed for 12 students of the third grade in the technology education course in a junior high school. 'The experimental class was performed in two school hours. The learning theme was "Let's investigate the mechanism of wind power gencration". The procedure of the class is shown as follows.

[The first school hour ]

1. Prior questionnaire survey concerning wind power generation and energy problems

2. Mechanisms of various power plants

Mechanisms of various kinds of power generation such as the thermal power. the nuclear power, the hydraulic power and the photovoltaic power

Circumstances of power generation in Japan at the present and in the future

3. Kinds and features of the new energy in Japan

4. Feature of photovoltaic generation

5. Advantage and disadvantage of wind power gencration

Presentation of students' opinions about the features of wind power generation

Present state of wind power generation in Japan and the world

6 . Kinds and structures of wind power generation

Principle and mechanism of wind power generation

Classification of windmill according to its shape

Understanding of the structure of wind power generation from the photographs

[ The second school hour ]

7. Learning of the structure of the tcaching tool 
Shape of blades of the teaching tool

Relation between wind flow and the blade

The idea to turn the blades lightly such as the magnetic levitating bearing

The necessity of the gears to accelerate rotation speed

Mechanism of power generation with the magnets and the coils

8. Experiment on power generation efficiency using dynamos

Two dynamos were connected directly. Ten rotations were given to one dynamo slowly or fast. respectively. Then, the number of rotations of the other dynamo was measured.

9. The experiments using the teaching tool

Relation between wind velocity and generated voltage

Relation between the shape of blades and generated voltage

Relation between gear shifting and generated voltage

Relation between the distance between the magnets and the coils and generated voltage

10. Summary of experiments

Consideration and presentation of the experimental results by students

Presentation of the efficient method of power generation

11. Discussion about energy saving by ourselves

Presentation of students' ideas to save electric energy effectively

12. Posterior questionnaire survey of learned knowledge concerning wind power generation and energy problems

13. Delayed questionnaire survey using the same questionnaire as the posterior survey three weeks after the class

\subsection{Results of the experimental class}

Table 1 shows the results of the prior questionnaire survey. In the prior survey, all students recognized wind power generation because they had seen photographs and images of wind power generation on television and magazines. However, there were extremely few students who could answer "Mechanism of wind power generation" and "Features of wind power generation" correctly, so scientific recognition about these items were not enough. Moreover, students with interest in energy problems were also extremely few.

In the class, however, we succeeded to raise the interest of the students by showing the concrete quantitative data such as the historical transition of the total capacity of the wind power generation in Japan and the world. Moreover, it is considered that the purpose of the experiments and the understanding of the mechanism were established cnough in the students because the operation state of the teaching tool could be visually confirmed. The students' opinions requesting more progressive experiments were derived. For example, "I want to compare the quantity of generated electricity by the horizontal axis type and the vertical axis type", "I want to investigate the relation between the shape of blades and the cut-in wind velocity", "I want to investigate the relation between the quantity of generated electricity and the number of magnets and coils" and so on. The interest for progressive learning was promoted as well as the understanding of the content of learning by the use of the teaching tool.

Table 1 Results of prior questionnairc survey

\begin{tabular}{lllll}
\hline Question & Recognition & Mechanism & Principle & Interest \\
\hline Correct answer & $12(100 \%)$ & $1(8 \%)$ & $2(16 \%)$ & $2(16 \%)$ \\
\hline
\end{tabular}

Table 2 shows the results of the posterior questionnaire survey and the delaycd survey. from the posterior survey, a very high correct answer rate was obtained about "1. Understanding of the mechanism of wind power generation" and "2. Indication of the features of wind power generation". Similarly, in the delayed survey afler three weeks, the 
decrease of the correct answer rate was very small, so that it was shown that the learned knowledge was established. This establishment of knowledge is considered to be due to the experiential learning through the experiments. Morcover, "3. Interest in encrgy problems" and "4. Necessity of energy saving" were also high. In the discussion about the energy saving that was done in the second hour, many students pointed out the necessity of promoting new energy and the concrete method of energy saving. The interest in energy problems could be also raised through the learning concerning wind power generation.

Table 2 Results of posterior questionnaire survey and delayed survey

\begin{tabular}{lcc}
\hline Question & Posterior survey & Delayed survey \\
\hline 1. Understanding of mechanism & $11(92 \%)$ & $10(83 \%)$ \\
2. Indication of features & $12(100 \%)$ & $11(92 \%)$ \\
3. Interest in energy problems & $10(83 \%)$ & $10(83 \%)$ \\
4. Necessity of energy saving & $9(75 \%)$ & $9(75 \%)$ \\
\hline
\end{tabular}

\section{Conclusions}

Although wind power generation is safe and clean energy, it is not enough spread because of the technical problems such as the installation place, the wind noise, the provision against strong wind and so on and the political problems such as the obligationless to the electric power companies to buy the surplus electricity and so on. Learning such energy circumstances earlier and deepening such understanding concerning new energy are an effective method to promote the students who positively participate in the energy and environment problems.

Using the developed teaching tool is considered to be effective in the following items.

1. The mechanism of wind power generation could be learned through the experiment and the measurement.

2. The fundamentals of the mechanical engineering such as the transmission structure of rotary motion and the idea to turn blades lightly could be learned.

3. The process that the rotary motion of the shaft as the mechanical energy converted into the electrical energy could be learned.

4. Interest of students in energy problems and energy saving could be raised.

5. The cost of materials of the teaching tool is about 20,000 Japanese yen, so that it is possible to introduce casily even in the school.

\section{References}

(1) Ministry of Education, Culture. Sports. Science and Technology in Japan. Curriculum guidance for defining the basic standard for education (2002), pp.16-30.

(2) Mada, Y. et al., Industrial arts and homemaking, Kairyudo (2006).

(3) NEDO, Safeguarding the Future of the Earth -NEDO's Activities in the Environment and Energy Fields -, NEDO Environment \& Energy Booklet (2006).

(4) Tanaka K., "Monozukuri", or creating things, that Arises from Desire "I Want to Make Things Myself" :One Bulb has been Lit,Sciense Education Monthly, Vol.53, No.624 (2004), pp.24-26.

(5) Matsunaga S., The handmade wind power gencrator. The Information Center for Encrgy and Environment Education Report 2003 (2003), pp.278-279.

(6) Yamamoto T., Makino R., Tamagawa N., Development of a Teaching Tool for Learning the Energy Conversion Experimentally and Lesson Practice -Development of Teaching Tools for Battery Charger made by Super Capacitors and Hybrid Electric Power Generation-, Journal of Saitama University (Faculty of Education), Vol.52, No.1 (2003), pp.69-76. 